\title{
An Experimental Study on Ship-Bank Hydrodynamic Interaction Forces
}

\author{
+ Chun-Ki Lee \\ *Assistant Professor, Division of Navigation Science, Korea Maritime University
}

\begin{abstract}
This paper is mainly concerned with the ship-bank interaction by model test. The experiments for the characteristics on hydrodynamic interaction forces and moments between vessel and bank with a mound were carried out in the seakeeping and maneuvering basin. A series of tests were carried out with ship model in parallel course along a vertical sidewall with a mound with varying lateral spacing between model ship and sidewall, length of sidewall and water depth. From the experimental results, it indicated that the hydrodynamic interaction effects increase as length of sidewall with a mound increases. Furthermore, for lateral spacing less than about $0.2 L$ between vessel and bank, it can be concluded that the bank effects increase largely as the lateral spacing between vessel and bank decreases. However, for spacing between vessel and bank more than about 0.3L, the interaction effects increase slowly as lateral spacing decreases. Also, for the water depth to draft ratio( $h / d)$ less than about 1.5, the hydrodynamic interaction effects increase dramatically as $h / d$ decreases.
\end{abstract}

Key words : Interaction, Bank effect, Water depth, Shape of bank, Spacing between ship and bank, Model test

\section{Introduction}

In confined waters, potential hazards of collision and grounding are maximum, and control errors could result in costly damages to both the ship and environment. So, the control of ships in confined waters, particularly in narrow channels, has been receiving a great deal of attention in recent years because of the ever-increasing size of ship such as tanker or bulk carrier. Also, the problem of ship controllability in confined waters due to the effect by restricted waterways, such as bank effect or shallow water effect is the concern not only of naval architects and ship operators but also of engineers who will design future waterways. So, the ship maneuvering and ship-bank interaction in confined water have been important problems in channel design and ship operation in harbours, and the problems are complicated because of the shallow water effects as well as ships are operating near banks or other ships. Therefore, the maneuvering motion due to the hydrodynamic interaction forces between ship and some fixed structure in restricted waterways, such as in a harbour or in a narrow channel has been of considerable interest because the safe operation and effective control of the vessel require a good understanding of the interaction forces that encounter. Meanwhile, a large number of papers in this field have been described on the hydrodynamic interaction forces between ship and some fixed structure, and some improved results were obtained(Davis, 1986, Kijima et al., 1991, Norrbin, 1974, Newman, 1969, Yasukawa, 2002, Yeung et al., 1980). However, in case of same size with the size of a ship length, there has been a lack of experimental data on the effects of sidewall with a mound affecting on the hydrodynamic force acting on a vessel, which is slowly moving in restricted waterways such as in the fixed structure, or in a narrow channel. Thus, in this paper, experimental conditions associated with the experimental setup are presented, and experimental results for the characteristic of hydrodynamic interaction forces acting on a vessel proceeding near the sidewall with a mound, and near the sidewall without mound are discussed.

\footnotetext{
† Corresponding author, leeck@hhu.ac.kr 051)410-4277

Note) This paper was presented on the subject of "An Experimental Study on Ship-Bank Hydrodynamic Interaction Forces" in 2013 Joint Conference KINPR proceedings(Republic of Korea Naval Academy, 27th-28th June, 2013, pp.15-16).
} 


\section{Experimental setup}

As shown in Fig. 1, the coordinate systems fixed on a ship and on the earth are shown by $o_{1}-x_{1} y_{1}$ and $o-x y$ respectively. The model moved in the direction of $x$-axis with velocity $U_{1}$, and $S_{P 1}$ and $S_{T 1}$ are lateral and longitudinal distance between side of model ship and vertical-sided objects. Experiments for the characteristic of hydrodynamic forces were carried out utilizing the general cargo vessel as a model ship as shown in Table. 1. Four separate experiments were performed and the hydrodynamic interaction forces on the model ship were measured under the following conditions as shown in Table. 2 :

1. Test of sidewall without mound(Type 1) - a straight, the lateral distance between the side of a model ship and the sidewall was varied for combinations of depth-to-draft ratio, $\mathrm{h} / \mathrm{d}=1.2,1.5,2.0$.

2. Test of sidewall with a mound(Type 2) - a straight, the lateral distance between the side of a model ship and the sidewall was varied of depth-to-draft ratio, $h / d=1.2$.

3. Test of sidewall with a mound(Type 3) - a straight, the lateral distance between the side of a model ship and the sidewall was varied of depth-to-draft ratio, $\mathrm{h} / \mathrm{d}=1.2$.

4. Test of sidewall with a mound(Type 4) - a straight, the lateral distance between the side of a model ship and the sidewall was varied of depth-to-draft ratio, $\mathrm{h} / \mathrm{d}=1.2$.

Also, all experiments were carried out in the condition that starting point is equal to about $-5.0 \mathrm{~L}$ from the center of mound and $F_{n}=0.08$.

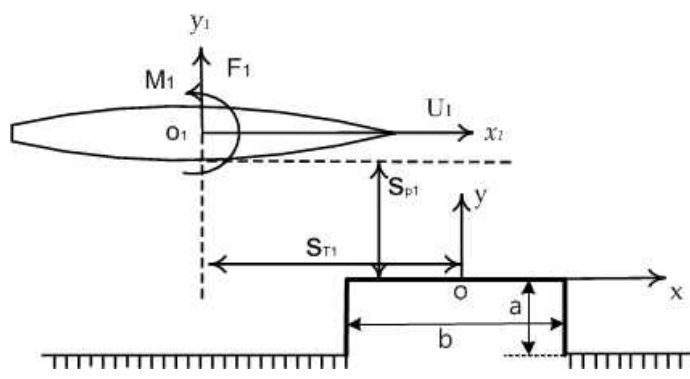

Fig. 1 Coordinate system

Table 1 Principle particulars

\begin{tabular}{|c|c|c|}
\hline \multirow{2}{*}{} & \multicolumn{2}{|c|}{ General cargo vessel } \\
\cline { 2 - 3 } & Model & Full Scale \\
\hline$L(m)$ & 2.5 & 155.0 \\
\hline$B(m)$ & 0.4194 & 26.0 \\
\hline$d(m)$ & 0.1403 & 8.7 \\
\hline$C_{B}$ & \multicolumn{2}{|c|}{0.6978} \\
\hline
\end{tabular}

Table 2 Types with parameters a and $\mathrm{b}$

\begin{tabular}{|c|c|c|}
\hline \multirow{2}{*}{ Types } & \multicolumn{2}{|c|}{ Length } \\
\cline { 2 - 3 } & $\mathrm{a}$ & $\mathrm{b}$ \\
\hline Type 1 & $0 \mathrm{~L}$ & $0 \mathrm{~L}$ \\
\hline Type 2 & $0.34 \mathrm{~L}$ & $0.34 \mathrm{~L}$ \\
\hline Type 3 & $0.34 \mathrm{~L}$ & $0.99 \mathrm{~L}$ \\
\hline Type 4 & $0.34 \mathrm{~L}$ & $2.3 \mathrm{~L}$ \\
\hline
\end{tabular}

In all following figures, the non-dimensional hydrodynamic force and moment coefficients are defined as follows:

$$
C_{F 1}=\frac{F_{1}}{0.5 \rho L d U_{1}^{2}}, C_{M}=\frac{M_{1}}{0.5 \rho L^{2} d U_{1}^{2}}
$$

Where, $\rho$ is the water density, and $\mathrm{L}$ is the ship length and $d$ is the ship's draft.

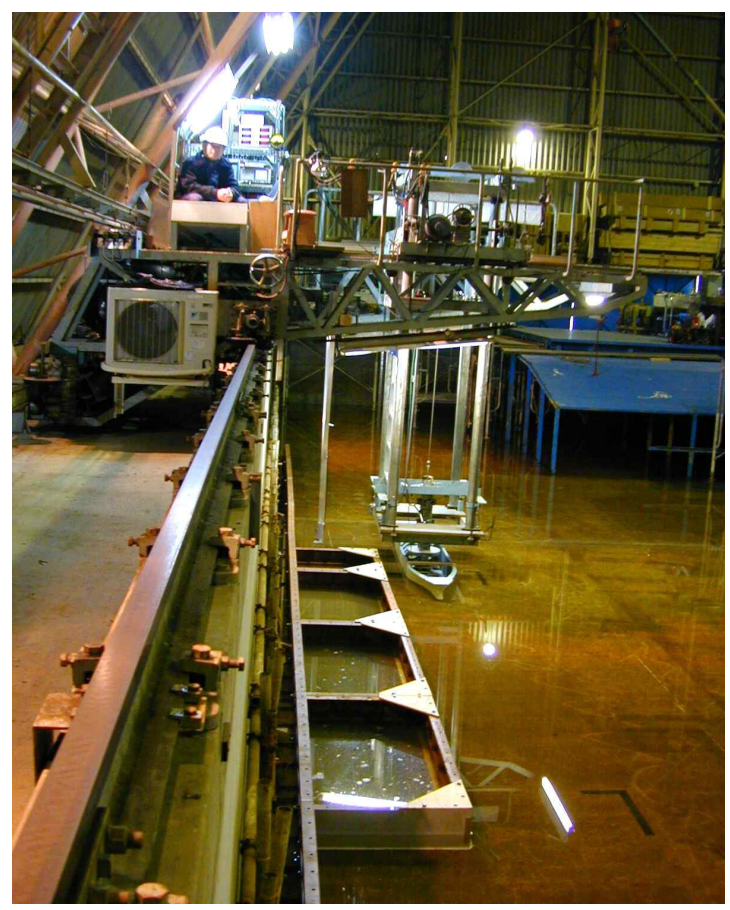

Fig. 2 A photograph of the experimental setup

The tests were conducted using a seakeeping and maneuvering basin in Kyushu University $(28 m \times 25 m)$. One rail runs on the sidewall without mound of the basin and the other rail runs on the lever. A photograph of the experimental setup is shown in Fig. 2. For the sidewall without or with a mound experiments, the sidewall was constructed using iron plate. Mounds were installed with connecting pieces joining their ends. Flathead bolts put through the perforations on the connecting pieces were adjusted to make the wall vertical, and a pointer 
temporarily erected on the carriage established the width accurately along the entire length.

\section{Experimental results of hydrodynamic interaction forces}

The hydrodynamic interaction forces and moments developed by the model due to the effects of a sidewall with a mound or sidewall without mound are shown in Fig. 3 to Fig. 7. Fig. 3 to Fig. 5 show the measured results of hydrodynamic interaction forces and moments acting on a vessel in transient motion past short and long sidewall with a mound by varying the length of mound in $S_{P 1} / L=0.1$. The lengths of mound, $\mathrm{b}$ were equal to $0.34 \mathrm{~L}, 0.99 \mathrm{~L}$ and 2.3L, respectively. A broken line represents the sidewall with a mound in these figures. From these figures, it indicates that the attracting force is dominant at all times if there is no sudden change of geometry on the boundary. The distinct higher-frequency oscillations occur before the interaction begins.
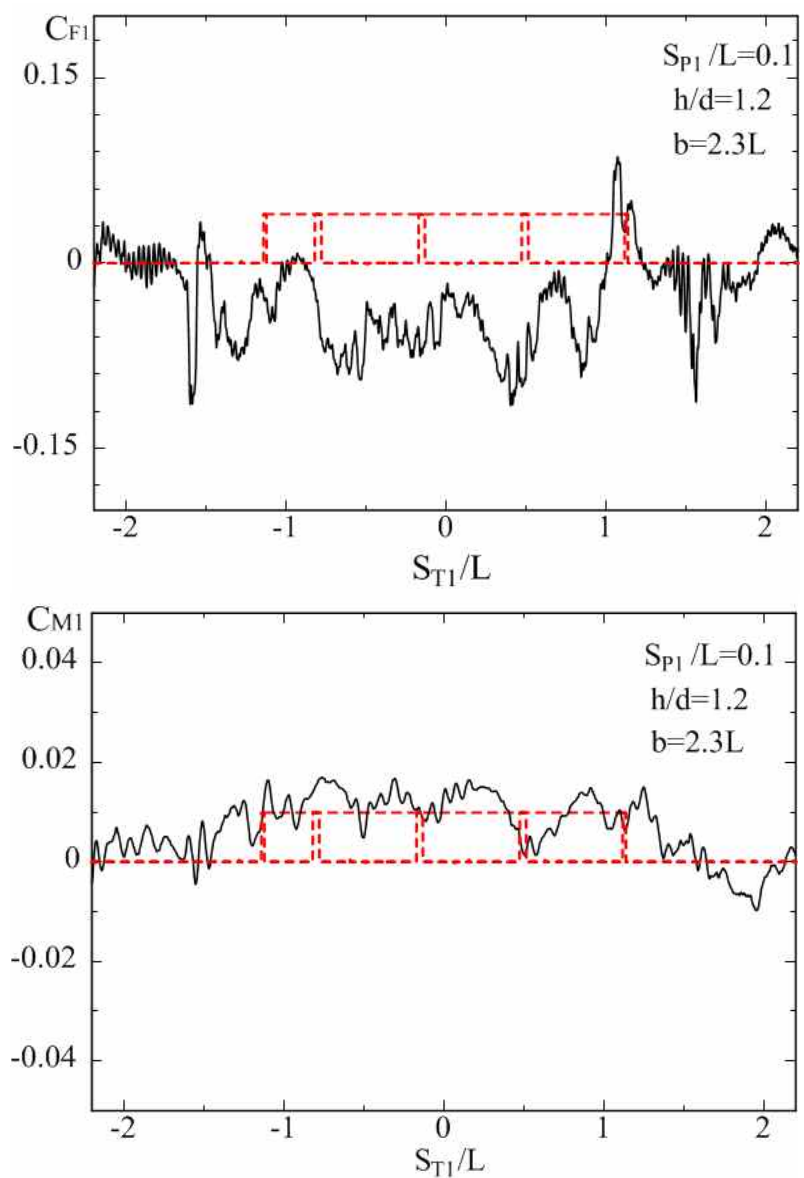

Fig. 3 Measured lateral force and yaw moment depending on the mound length $\mathrm{b}\left(\mathrm{b}=2.3 \mathrm{~L}, S_{P 1} / L=0.1\right)$
They are almost identical on all runs and apparently are caused by the waves generated by the moving model when it starts up, and also caused by the basin as it moves by the fixed model. Also, these oscillations are the result of noise caused by disturbance such as train or airplane. And also, when the vessel is far from the leading edge of a sidewall with a mound, there is only a so-called steady bank suction force acting on a vessel. Then the vessel experiences an attracting force which increases as the vessel approaches the sidewall with a mound. When its bow approaches the leading edge of a mound, the vessel encounters the first hump of the attracting force and a small bow-outward moment. Then the interaction forces decrease quickly. The maximum repulsive force is achieved when the midship of a ship passes the midship of a mound Then the sway force reverses to attain the steady attracting force associated with the motion alongside an infinite bank.
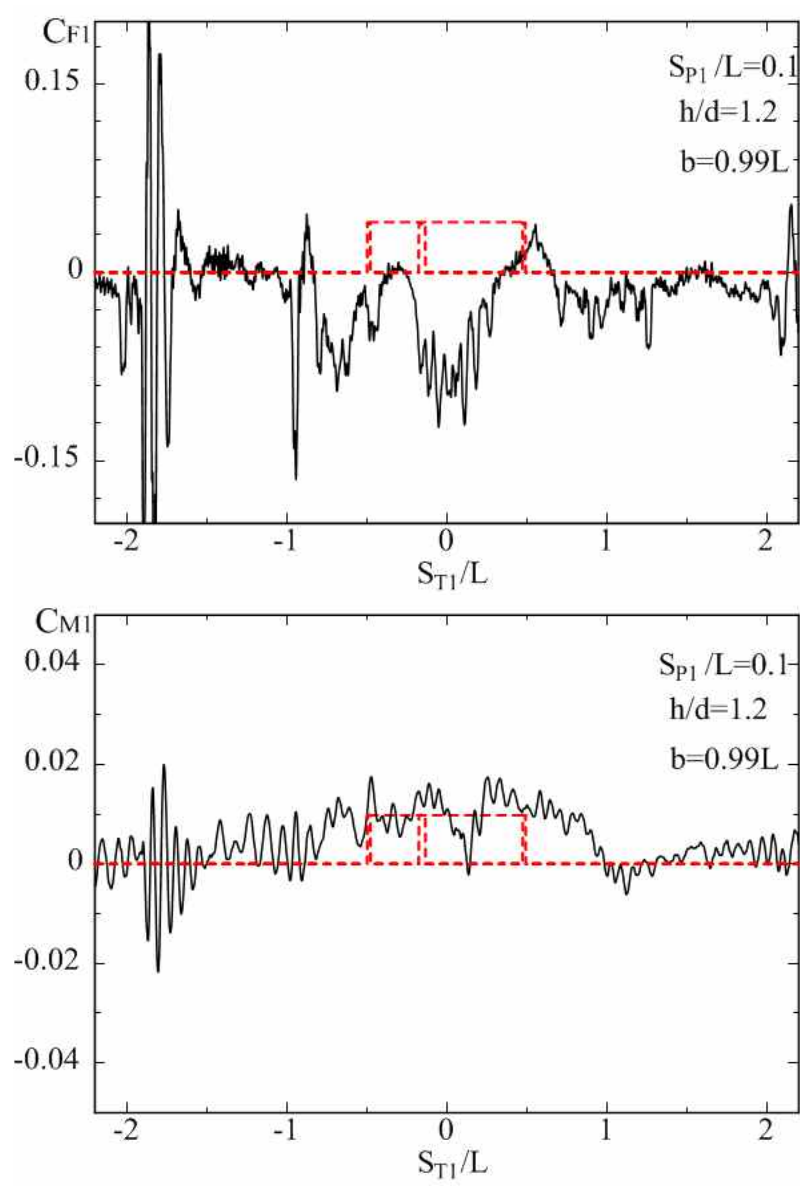

Fig. 4 Measured lateral force and yaw moment depending on the mound length $\mathrm{b}\left(\mathrm{b}=0.99 \mathrm{~L}, S_{P 1} / L=0.1\right)$ 

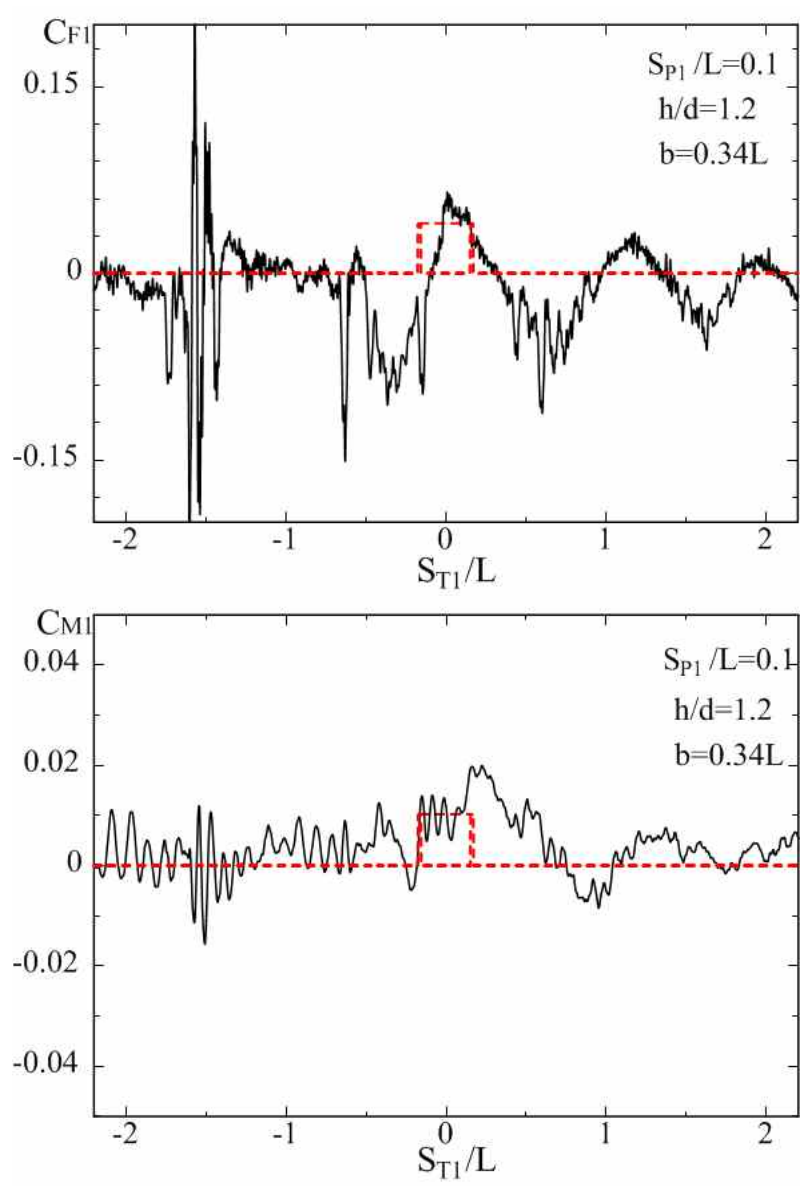

Fig. 5 Measured lateral force and yaw moment depending on the mound length $\mathrm{b}\left(\mathrm{b}=0.34 \mathrm{~L}, S_{P 1} / L=0.1\right)$

The vessel experiences a maximum bow-outward moment when its midship is about at the midship of a sidewall with a mound, then there is a steady bow-inward moment acting on the vessel as it leaves the mound. Also, the experimental results showed that the hydrodynamic interaction forces acting on the vessel get increased, and the regions for this become wider as the length of mound increases. The steady interaction forces under this condition was also acted. However, it is recognized that if the length of a mound is sufficiently shorter than the one of a ship, the interaction forces are getting smaller. Furthermore, regardless of the length for the mound, it indicated that the hydrodynamic forces acting on the vessel represent almost qualitatively same tendency, when the midship of a ship was about 0.5 times of a ship length from the leading edge of a sidewall with a mound.

In the meantime, the experimental results for a vessel passing by a sidewall without mound are illustrated in Fig. 6 and Fig. 7. In these figures, the steady bank suction force and bow-outward moment are acted. These figures represent the measured results with function of depth-to-draft ratio, h/d. Fig. 6 shows the measured hydrodynamic interaction force and moment between vessel and bank when a vessel passes near the bank without mound and water depth to draft ratio of $1.2(\mathrm{~h} / \mathrm{d}=1.2)$ under the condition of $S_{P 1}=0.1 \mathrm{~L}$. Also, Fig. 7 displays the measured hydrodynamic interaction force and moment between vessel and bank when a vessel passes near the bank without mound and water depth to draft ratio of 2.0 (h/d=2.0) under the condition of $S_{P 1}=0.1 L$. As expected, the magnitude of values for the hydrodynamic interaction force and moment decreases as water depth to draft ratio $(\mathrm{h} / \mathrm{d})$ increases.
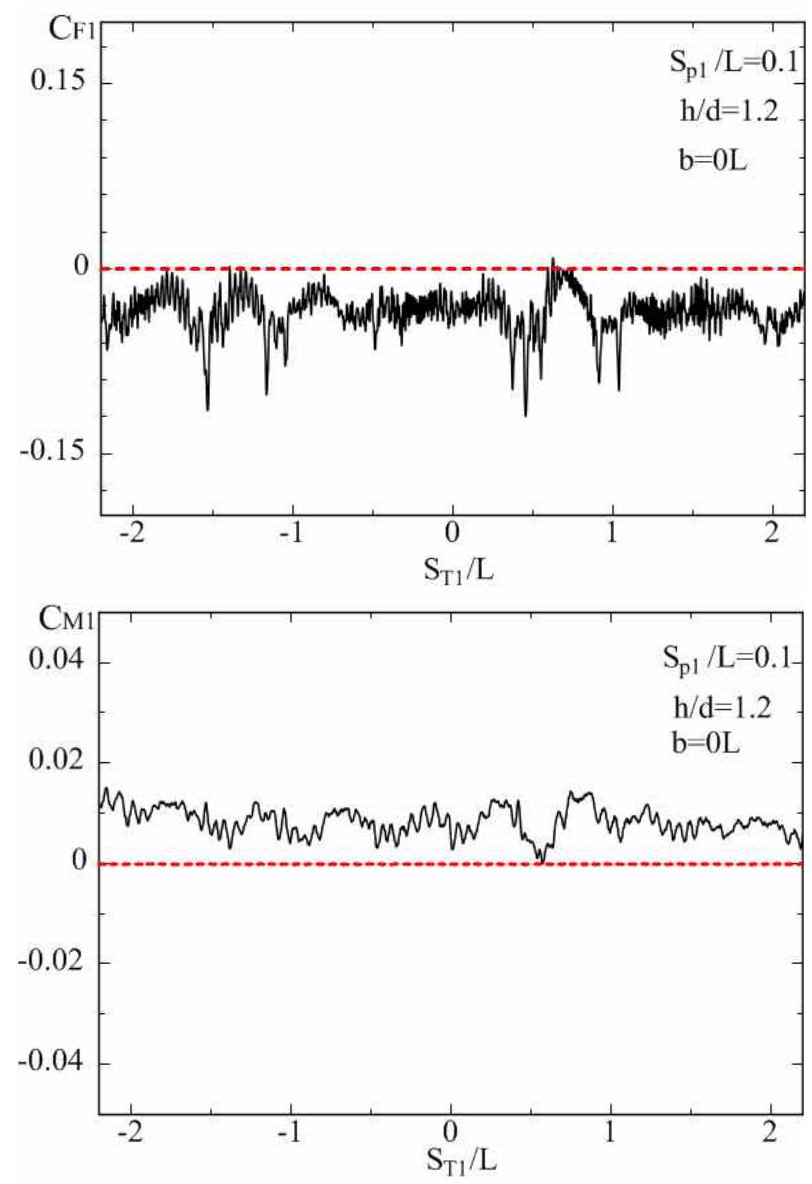

Fig. 6 Measured lateral force and yaw moment with variation of $\mathrm{h} / \mathrm{d}$, and spacing between ship and sidewall $\left(\mathrm{b}=0 \mathrm{~L}, \mathrm{~h} / \mathrm{d}=1.2, S_{P 1} / L=0.1\right)$ 

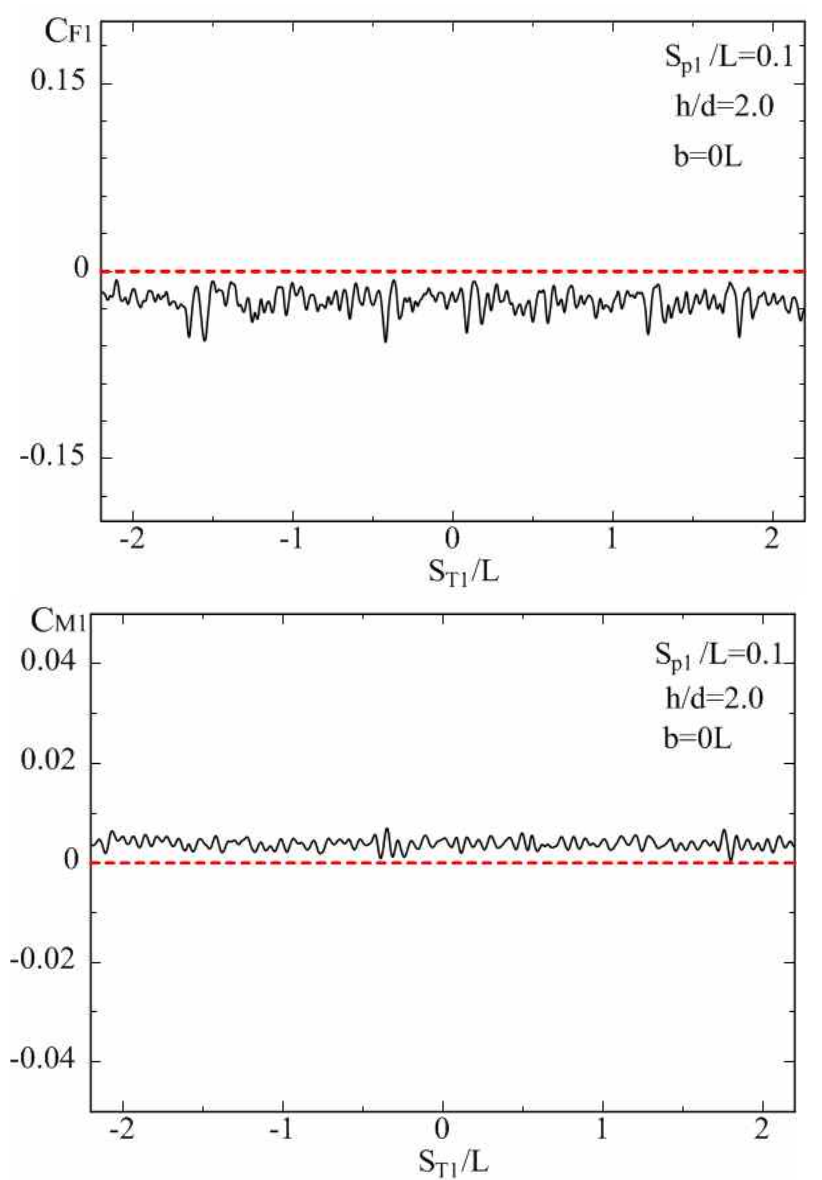

Fig. 7 Measured lateral force and yaw moment with variation of $\mathrm{h} / \mathrm{d}\left(\mathrm{b}=0 \mathrm{~L}, \mathrm{~h} / \mathrm{d}=2.0, S_{P 1} / L=0.1\right)$

Fig. 8 displays the mean value of experimental result for measured hydrodynamic interaction force and yaw moment between leading and ending edge of a mound. In case of Type $1(b=0 \mathrm{~L})$ as shown in Table 2, the average value of -2.0 to 2.0 in $S_{T 1} / L$ was taken in Fig. 8 .

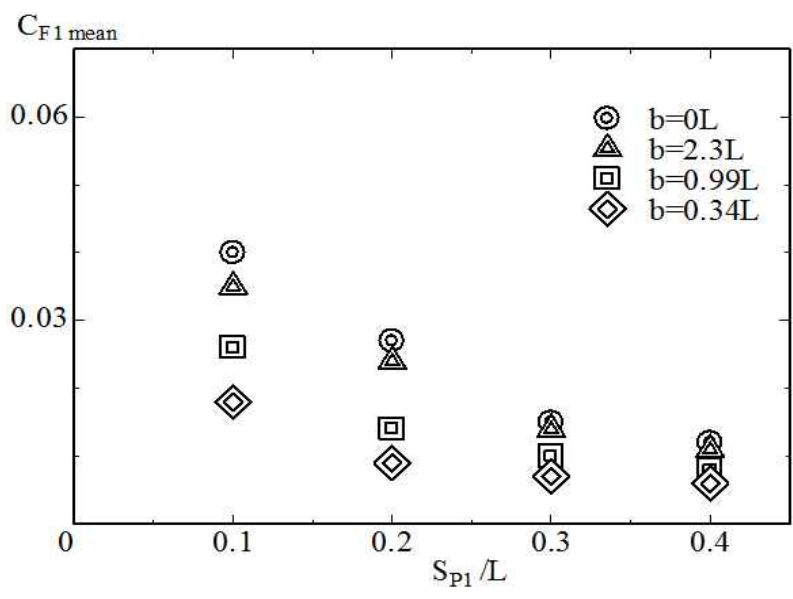

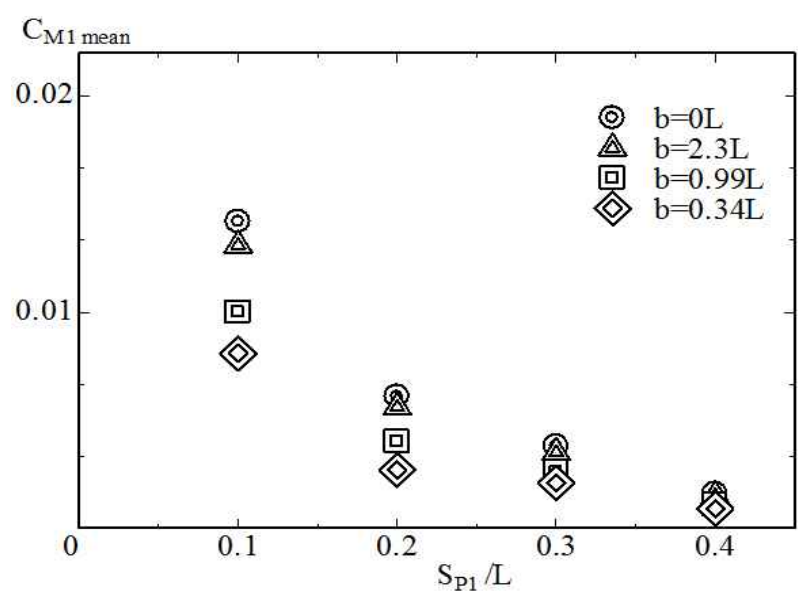

Fig. 8 Comparison of measured lateral force and moment with variation of mound length $(\mathrm{h} / \mathrm{d}=1.2)$
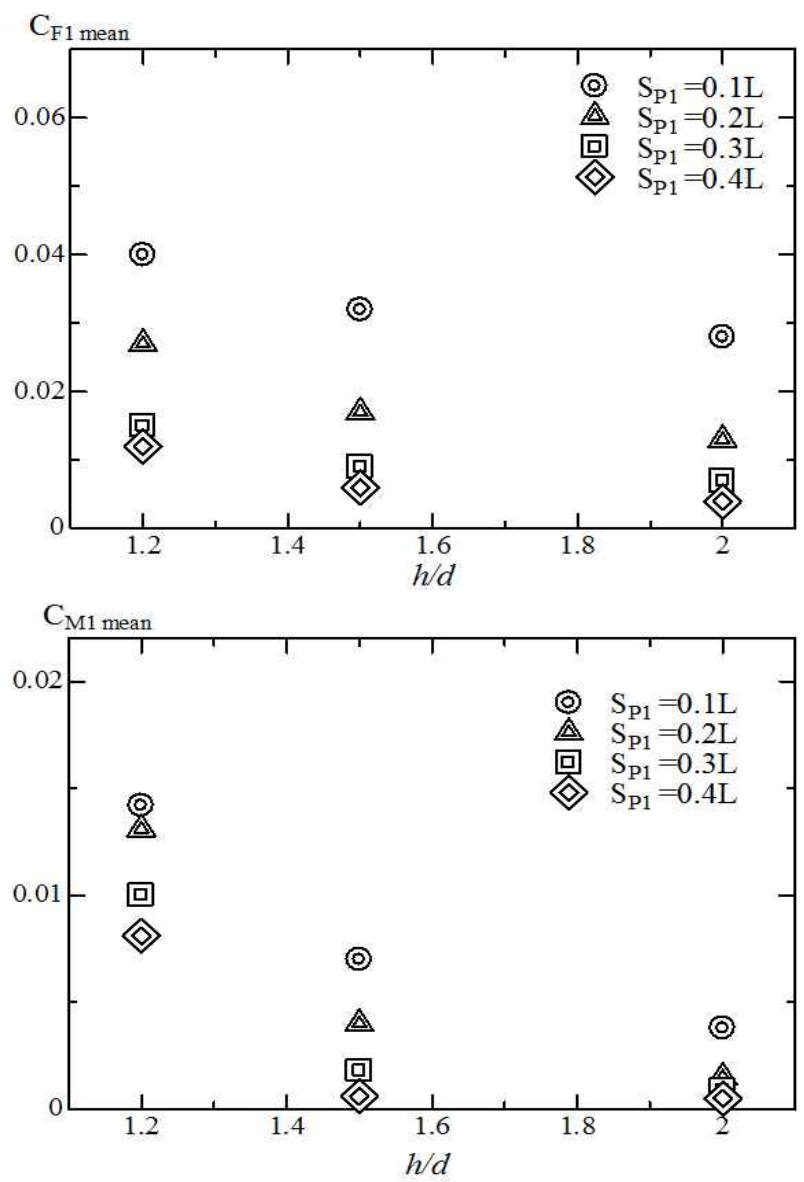

Fig. 9 Comparison of measured lateral force and momentwith variation of $\mathrm{h} / \mathrm{d}(\mathrm{b}=0 \mathrm{~L})$

Fig. 8 shows the result of lateral force and yaw moment coefficient acting on a model ship with variation of mound length and $S_{P 1}$. As expected, the magnitude of values for the hydrodynamic force and moment decreases as the lateral separation distance, $S_{P 1} / L$, increases. Also, the 
experimental results for a vessel passing by a sidewall without mound $(b=0 L)$ with function of depth to draft ratio (h/d) and lateral spacing between ship and bank are illustrated in Fig. 9. As expected, the magnitude of values for the hydrodynamic interaction force and moment decreases as water depth to draft ratio ( $h / d)$ increases. Also, for the water depth to draft ratio(h/d) less than about 1.5 , the hydrodynamic interaction effects increase largely as $\mathrm{h} / \mathrm{d}$ decreases.

\section{Conclusions}

In this research, the ship-bank hydrodynamic interaction forces and moments for the sake of reducing marine disasters in restricted waters were determined by model test between ship and sidewall with a mound. The following conclusions can be drawn from the experimental results for interaction effect.

First, in case of ship-sidewall with a mound interaction effect, significant changes arose at the leading and ending edge of a mound, and as the length of mound increases the hydrodynamic force and moment increases.

Second, when passing at low speed of about $F_{n}=0.08$ near the sidewall with a mound, the hydrodynamic interaction force sharply increases as the lateral separation distance between ship and sidewall decreases when the spacing between ship and sidewall with a mound is less than about 0.2 times of ship length. However, when spacing is more than about 0.3 times of ship length, the interaction effect dramatically decreases as the lateral distance increases.

Third, in case of this experimental research under the condition of without mound, ship-sidewall interaction effect dramatically increases as water depth decreases when water depth to draft ratio, $\mathrm{h} / \mathrm{d}$, is lower than about 1.5 .

In the near future the ship-bank interaction effect measured in this paper will be carried out by model test under the condition of different shape of mound.

In conclusion, the experimental results of this research will be convenient to be used for constructing a traffic safety system of ship maneuvering near the restricted waters, such as avoiding crashing accidents, constructing an automatic controlling system, making an ocean traffic control system, and building safe harbours.

\section{References}

[1] Davis, A. M. J.(1986), "Hydrodynamic Effects of Fixed Obstacles on Ships in Shallow Water", Journal of Ship Research, Vol. 30. pp. 94-102.

[2] Kijima, K, Furukawa, Y. and Qing, H.(1991), "The Interaction Effects between Two Ships in the Proximity of Bank Wall", Trans. of the West-Japan Society of Naval Architects, Vol. 81, pp. 101-112.

[3] Newman, J. N.(1969), "Lateral motion of a slender body between two parallel walls", J. Fluid Mech., Vol. 39. pp. 97-115

[4] Norrbin, N. H.(1974), "Bank effects on a Ship Moving Through a Short Dredged Channel", Proc. 10 Symposium on Naval Hydrodynamics, Cambridge. pp. $52-63$.

[5] Yasukawa, W.(2002), "Ship Manuevering Motions in the Proximity of Bank", Trans. of the West-Japan Society of Naval Architects, Vol. 104. pp. 41-52.

[6] Yeung, R. W. and Tan, W. T.(1980), "Hydrodynamic Interactions of Ships with Fixed Obstacles", Journal of Ship Research, Vol. 24. pp. 50-59.

Received 14 May 2013

Revised 12 June 2013

Accepted 12 June 2013 